\title{
Testing of smoothed particle hydrodynamics method for minor loss coefficient in three-dimensional water flow in circular vertical pipe contraction
}

\author{
Muhammad Irham Sya'bani ${ }^{1, *}, R$ R Dwinanti Rika Marthanty ${ }^{1}$, Herr Soeryantono ${ }^{1}$, and Jessica Sjah $^{1}$ \\ ${ }^{1}$ Civil Engineering Department, Faculty of Engineering, Universitas Indonesia, Depok, Indonesia
}

\begin{abstract}
Smoothed Particle Hydrodynamics method has been developed rapidly as an alternative numerical method to solve the fluid physics problem. This meshless method is able to identify the physical entity of each fluid by interpolating the corresponding physical entity associated with the neighboring particles within the influence domain. Three-dimensional fluid flows on circular vertical pipe contraction were studied by using this method. The numerical model will be simulated by varying the number of fluid particles and the number of kernel particles within the influence domain. The conservation of mass, conservation of energy and the minor loss coefficient will be evaluated. The mass conservation and energy conservation will be reached by considering the appropriate number of initial particles and kernel particles. The results of the minor loss coefficient achieved from the numerical simulation are between 1.992 and 2.836 .
\end{abstract}

\section{Introduction}

\subsection{Background}

Smoothed Particle Hydrodynamics (SPH) Method used as one alternative numerical method to solve the fluid physics problem has developed rapidly. Not like the grid-based method, SPH method does not depend on the free surface, deformable boundary, and node variables that change in space and time.

One of the testings that use the SPH method for simulating three-dimensional flow on vertical pipe contraction has been researched before by Lydiana (2017) [1] with the rectangular vertical pipe model. The research uses the conservation law of mass and the conservation law of energy to observe the stability of the results. The results obtained were stable enough according to the variations of the total particles number used. However, due to using the rectangular pipe, the observation of particles' properties on simulation is limited to $\mathrm{x}$-axes and $\mathrm{z}$-axes particles, while the $\mathrm{y}$-axes particle does not give a significant difference. Therefore, the observation of $y-$ axes particles is negligible. As a result, the simulation represents as two-dimensional water flow behavior. Here our study interested to get the condition of threedimensional flow, the development is done with considering the y-axes particles changing the vertical pipe from the rectangular vertical pipe to circular vertical pipe, so it can be reached the realistic result for the real condition of three-dimensional flow.
The objective of this paper is to observe the stability of this testing by evaluating the conservation law of mass and the conservation law of energy. Moreover, the minor loss as one of the studied parameters will be computed.

This numerical simulation uses a compiler program, FORTRAN, to do the computation of the flow simulation. The variations of the total particles number and kernel particles used as the input parameter to observe the convergence of the simulation output.

\subsection{Novelty}

This research is the development of the research that is done before by Sitepu (2017) [2] and Lydiana (2016, 2017) $[1,3]$. This research will modify the vertical pipe from the rectangular vertical pipe [1,2,3] to circular vertical pipe, so it shows the realistic behavior on fluid flow in a pipe because the observation the particles done through on three-dimensional coordinate and the condition of the three-dimensional flow is formed automatically. The evaluation of the simulation will be added with the observation of the minor loss on the quantification of the conservation law of energy on the conical funnel.

\subsection{Scope}

Based on the background of this study, the limitations of this research are

\footnotetext{
* Corresponding author: irhamsb@gmail.com
} 
- The phenomenon of three-dimensional flow from the continuous fluid flow.

- The flow is the incompressible flow, so the density of the fluid is relatively constant.

- The loss observed is only at the particles pass through the contraction, so the minor loss is obtained.

- The friction between particle and pipe is neglected so the major loss is neglected.

\section{Literature}

\subsection{Smoothed particle hydrodynamics}

Smoothed Particle Hydrodynamics method is the meshfree, Lagrangian approach, particle method to model fluid flow [4].

Smoothed Particle Hydrodynamics method use the interpolation to estimate the value and derivation from continuous quantity with using the discrete particles. Particle is identified as the smoothed particle that carries the fluid entity, such as mass, position, velocity, and other entities, but the particles is also able to carry the physical property that can be estimated depend on the problem, such as density, temperature, pressure, and other properties [5].

Smoothed Particle Hydrodynamics method simulate fluid flow as the form of Navier-Stokes equation. The Navier-Stokes equation for the incompressible flow is

$$
\rho \frac{\partial u}{\partial t}=-\nabla p+\mu \nabla \cdot(\nabla u)+f
$$

where $\rho$ is the density, $\frac{\partial u}{\partial t}$ is the derivation of velocity to time, $-\nabla p$ is the pressure force, $\mu \nabla \cdot(\nabla u)$ is the viscosity force, and $f$ is the external force.

Navier-Stokes equation is simplified to be the acceleration as the total of the value of force that affect to the particle either the internal force or the external force. Those values will be quantified by doing the discretation then used for simulating fluid flow.

Density

$$
\rho_{i}=\sum_{j} m_{j} W\left(r_{j}-r_{j}, h\right)
$$

Internal force :

- Pressure force

$$
f_{i}^{\text {pressure }}=-\sum_{j \neq i}\left(\frac{p_{i}+p_{j}}{2}\right) \frac{m_{j}}{\rho_{j}} \nabla W\left(r_{i}-r_{j}, h\right)
$$

- Viscosity force

$$
f_{i}^{v i s \cos i t y}=\frac{\mu}{\rho_{i}} \sum_{j \neq i}\left(u_{j}-u_{i}\right) m_{j} \nabla^{2} W\left(r_{i}-r_{j}, h\right)
$$

External force :

- Gravity force

- Bouyancy force

$$
f_{i}^{\text {gravity }}=\rho_{i} g
$$

$$
f_{i}^{\text {bouyancy }}=b\left(\rho_{i}-\rho_{o}\right) g
$$

- Surface tension

$$
f_{i}^{\text {surface }}=-\sigma \frac{n_{i}}{\left\|n_{i}\right\|}\left(\sum_{j} \frac{m_{j}}{\rho_{j}} \nabla^{2} W\left(r_{i}-r_{j}, h\right)\right)
$$

\subsection{The conservation law of mass and energy}

The conservation law of mass equation is written as follow

$$
\frac{d}{d t} \int_{c . v} \rho d \forall+\int_{c . s} \rho(V \cdot \hat{n}) d A=0
$$

The conservation law of energy equation is written as follow

$$
\frac{d}{d t} \int_{c . v}\left(\frac{V^{2}}{2}+g z\right) \rho d \forall+\int_{c . s}\left(\frac{V^{2}}{2}+g z+\frac{p}{\rho}\right) \rho(V \cdot \hat{n}) d A+h_{L} \dot{m} g=0
$$

The head loss that is used in this research is the minor loss due to the changed turbulence on the contraction. As the head loss is obtained, the value of $h_{L}$ as an input to compute minor loss coefficient, $K$ by using least square method can be written as

$$
h_{L}=\frac{K}{2 g}\left(\bar{V}_{\text {out }}-\bar{V}_{\text {in }}\right)^{2}
$$

with $\bar{V}_{\text {out }}$ is the velocity of particle that exits the control surface and $\bar{V}_{i n}$ is the velocity of particle that enters the control surface.

\section{Research methodology}

\subsection{Model boundary}

The geometry of model simulated on this testing is circular vertical pipe with conical funnel as the contraction. The circular vertical pipe is divided into three segments as shown in Figure 1.

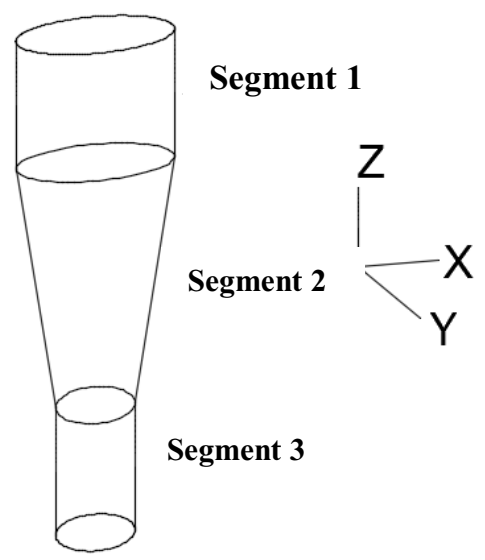


Fig. 1. Circular vertical pipe model

The dimensions of the model for diameter and pipe length could be seen in Table 1.

Table 1. Dimensions of circular vertical pipe model

\begin{tabular}{|l|c|c|c|}
\hline & Segment 1 & Segment 2 & Segment 3 \\
\hline Diameter $(\mathrm{m})$ & 0.5 & 0.5 to 0.25 & 0.25 \\
\hline Pipe length $(\mathrm{m})$ & 0.4 & 0.75 & 0.4 \\
\hline
\end{tabular}

The particle will flow vertically from segment 1 to segment 3 . The position of each particles on $x, y$, and $z-$ axes will be randomly distributed on segment model. The initial velocity of the particle is fixed at $0.0 \mathrm{~m} / \mathrm{s}$ on $\mathrm{x}, \mathrm{y}$, and $\mathrm{z}$-axes.

\subsection{Numerical parameter}

The numerical parameter of fluid based on Kelager [5] that shown in Table 2.

Table 2. Numerical parameter

\begin{tabular}{|l|l|l|l|}
\hline Description & Symbol & Value & Unit \\
\hline Rest Density & $\rho_{o}$ & 998.29 & $\begin{array}{l}\mathrm{kg} . \mathrm{m}^{-} \\
3\end{array}$ \\
\hline Particle Mass & $m$ & 0.02 & $\mathrm{~kg}$ \\
\hline $\begin{array}{l}\text { Bouyancy } \\
\text { Diffusion }\end{array}$ & $b$ & 0 & $\mathrm{na}^{-1}$ \\
\hline Viscosity & $\mu$ & $3.5\left(1.003 \times 10^{-3}\right)$ & $\mathrm{Pa} . \mathrm{s}$ \\
\hline Surface Tension & $\sigma$ & 0.0728 & $\mathrm{~N}^{-1}$ \\
\hline Threshold & $l$ & 7.065 & $\mathrm{na}^{-1}$ \\
\hline Gas Stiffness & $k$ & 3 & $\mathrm{~J}$ \\
\hline Restitution & $c_{R}$ & 1 & $\mathrm{na}^{-1}$ \\
\hline
\end{tabular}

\subsection{Smoothed particle hydrodynamics algorithm}

The initial input for this computation is the number of particles, the number of kernel particles, and the initial velocity. The number of iteration and timestep needed is manually input. At each iteration, the initial input will calculate the particle density and pressure, which are needed to calculate the force obtained from each particle. This calculation will result the particle acceleration based on Navier-Stokes equation. The particle position and velocity are assumed zero at initial iteration and will calculate with the particle acceleration using the leap-frog scheme to update the particle position and velocity.

Those variables obtained will be used to produce the output data needed for evaluation. The evaluation needed is to fulfill the conservation of mass and energy law equation based on the variables obtained from the quantification of the equation. To observe the stability of condition of conservation of mass and energy, it can use the residue of the total mass and energy. Meanwhile, to observe the stability of condition of head loss, the computation of this testing will obtain the value of head loss in segment 2.

The computation of smoothed particle hydrodynamics to simulate fluid flow using Langrangian approach is able to be done by this flowchart on Figure 2 .

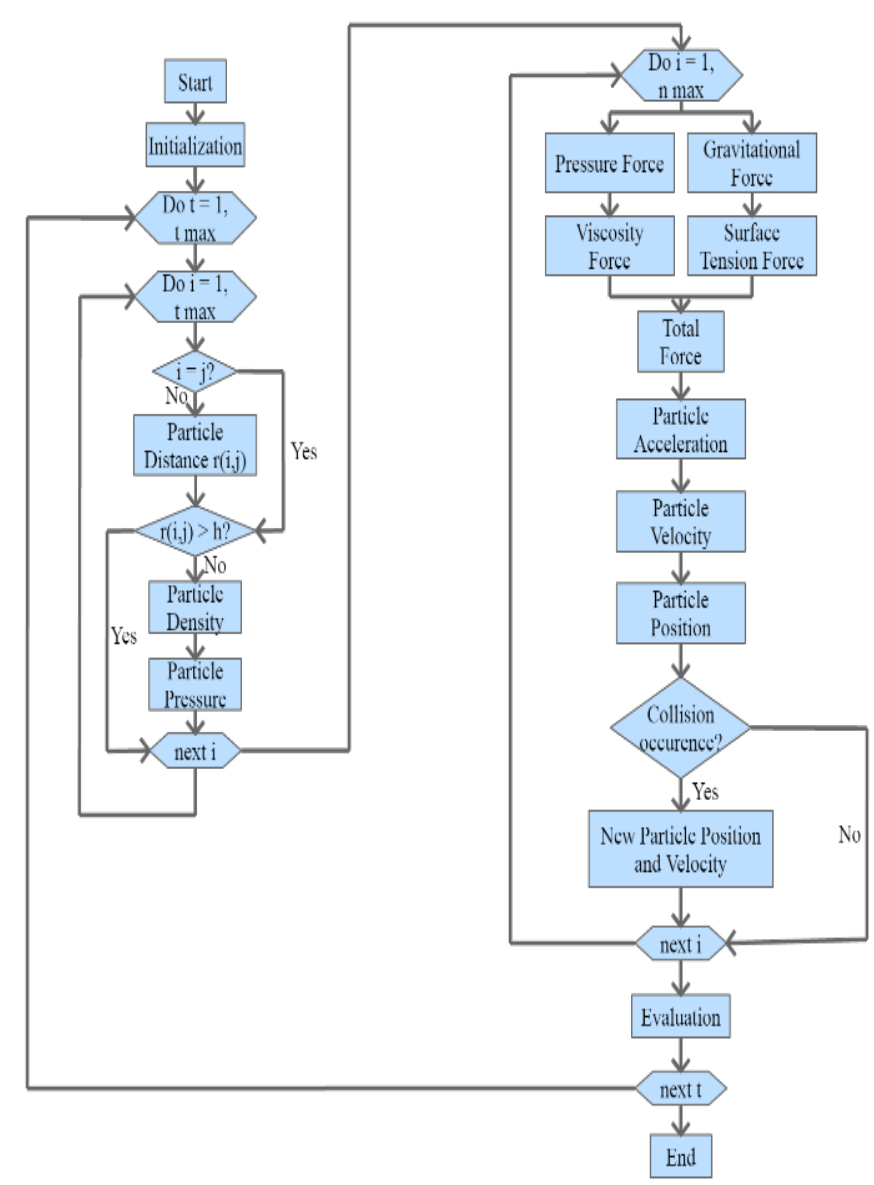

Fig. 2. Flowchart of smoothed particle hydrodynamics computation

\subsection{The scenarios of simulation}

The simulation each scenario will be performed on 100 iterations with the timestep on each iteration is $0.01 \mathrm{~s}$. The stability of simulations was achieved by using 100 iterations. The scenarios used for the model is based on the variation of initial particles and the kernel particles used in the support radius which are shown in Table 3.

Table 3. Scenarios of model simulation

\begin{tabular}{|c|c|c|c|c|c|}
\hline & \multicolumn{4}{|c|}{ Kernel Particles (x) } \\
\hline & & 10 & 12 & 15 & 17 \\
\hline \multirow{4}{*}{ 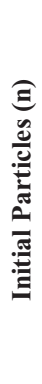 } & 2500 & $\begin{array}{c}\mathrm{n}= \\
2500, \\
\mathrm{x}=10\end{array}$ & $\begin{array}{c}\mathrm{n}= \\
2500 \\
\mathrm{x}=12\end{array}$ & $\begin{array}{c}\mathrm{n}= \\
2500 \\
\mathrm{x}=15\end{array}$ & $\begin{array}{c}\mathrm{n}= \\
2500 \\
\mathrm{x}=17\end{array}$ \\
\hline & 5000 & $\begin{array}{c}\mathrm{n}= \\
5000 \\
\mathrm{x}=10\end{array}$ & $\begin{array}{c}\mathrm{n}= \\
5000 \\
\mathrm{x}=12\end{array}$ & $\begin{array}{c}\mathrm{n}= \\
5000 \\
\mathrm{x}=15\end{array}$ & $\begin{array}{c}\mathrm{n}= \\
5000, \\
\mathrm{x}=17\end{array}$ \\
\hline & $\begin{array}{c}1000 \\
0\end{array}$ & $\begin{array}{c}\mathrm{n}= \\
10000 \\
\mathrm{x}=10\end{array}$ & $\begin{array}{c}\mathrm{n}= \\
10000 \\
\mathrm{x}=12\end{array}$ & $\begin{array}{c}\mathrm{n}= \\
10000 \\
\mathrm{x}=15\end{array}$ & $\begin{array}{c}\mathrm{n}= \\
10000, \\
\mathrm{x}=17\end{array}$ \\
\hline & $\begin{array}{c}1250 \\
0\end{array}$ & $\begin{array}{c}n= \\
12500, \\
x=10\end{array}$ & $\begin{array}{c}\mathrm{n}= \\
12500, \\
\mathrm{x}=12\end{array}$ & $\begin{array}{c}n= \\
12500, \\
x=15\end{array}$ & $\begin{array}{c}n= \\
12500, \\
x=17\end{array}$ \\
\hline
\end{tabular}

\section{Results and discussion}

The observation of the model was done on three segments on pipe. Model simulation results are based on each 
scenario can be seen based on the density obtained to refer to incompressible flow condition. The incompressible flow condition will be achieved by the condition of constant density. This condition was obtained by computing the difference between the average density on control volume and the total density of particles that enter the segment as the density change. The percentage of the density change obtained is shown Figure 3.

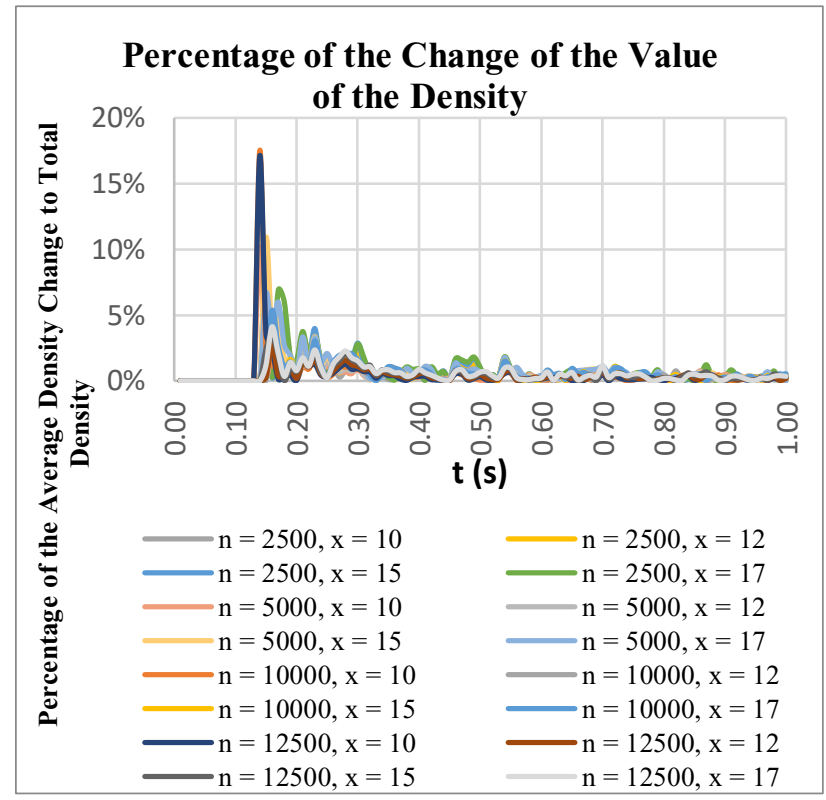

Fig. 3. The percentage of density change to total density

The percentage have the increase result on $t=0.12 \mathrm{~s}$ to $t=0.2 \mathrm{~s}$ on all scenarios due to the instability of the simulation when the particles just enter the observation segment then the result was decreased near to zero percent on the next $t$. Therefore, the simulation reaches the incompressible flow condition.

The calculation of the evolution of the mass and energy conservation law will obtain the value of residue. This residue value is influenced by the total change of calculation in control volume and total flux through the control surface. This value of residue can be used to evaluate the stability of simulation. The residue value for calculation of mass conservation law with $\mathrm{n}=12500$ particles is shown on Figure 4. Similar results were obtained for $n=2500,5000,10000$ particles.

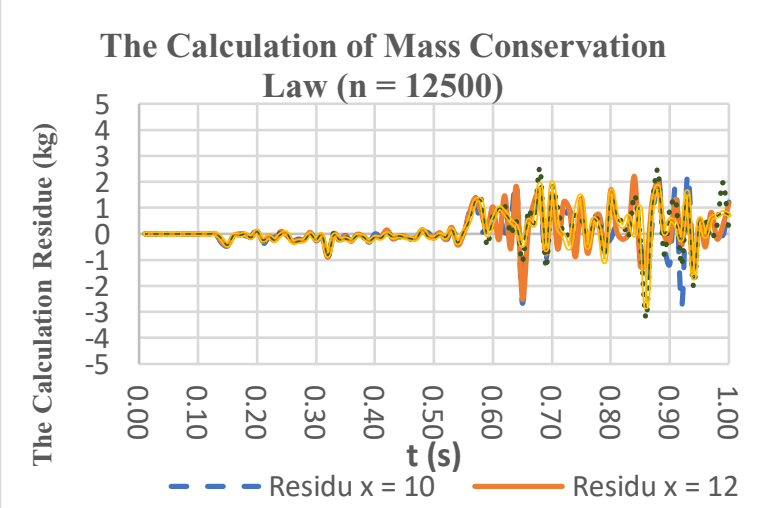

Fig. 4. The calculation of residue value for mass conservation law $(\mathrm{n}=12500)$
The graphs on Figure 4 shows that the fluctuation of the residue value of mass conservation law near zero. The fluctuation, start from $t=0.56 \mathrm{~s}$, become high although the fluctuation still under 4 Joule. Therefore, this simulation reaches the stability and it is able to reach the conservation law of mass.

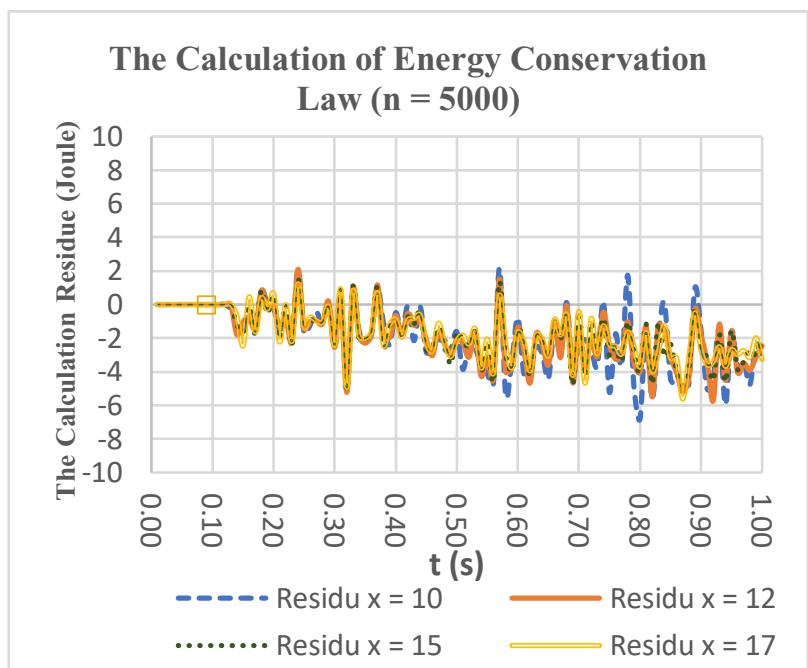

Fig. 5. The calculation of residue value for energy conservation law $(\mathrm{n}=5000)$

\section{The Calculation of Energy Conservation Law $(n=10000)$}

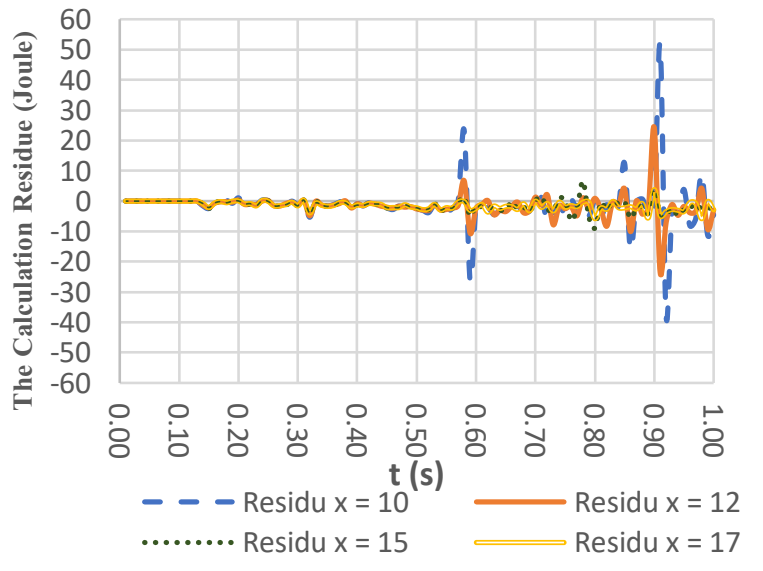

Fig. 6. The calculation of residue value for energy conservation law $(\mathrm{n}=10000)$

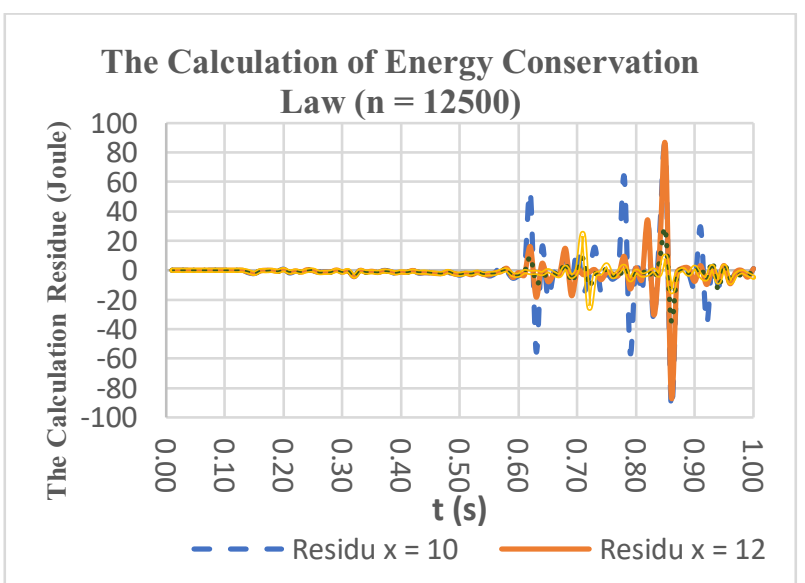

Fig. 7. The calculation of residue value for energy conservation law $(\mathrm{n}=12500)$ 
The residue value of energy conservation law with $\mathrm{n}=$ 5000,10000 , and 12500 particles are shown respectively in Figure 5 to Figure 7. The residue value for $n=2500$ particles give the similar result with one of $n=5000$, particles, which the result is fluctuating although it is under 7 Joule. Therefore, the results of $n=2500$ and 5000 particles reach the stability of simulation. However, for $\mathrm{n}$ $=10000$ and 12500 particles, there is important fluctuation when it used kernel particles of $\mathrm{x}=10$ and 12 particles. Therefore, for simulation studied of $n$ larger than 10000 particles, it needed the adjustment for the kernel particles used to reach the stability of simulation.

The value of minor loss coefficient obtained for each simulation based on the initial particles and kernel particles used is shown in Table 4 .

Table 4. Minor loss coefficient on each scenarios.

\begin{tabular}{|c|c|c|c|c|c|}
\hline & \multicolumn{4}{|c|}{ Kernel Particles (x) } \\
\hline & & 10 & 12 & 15 & 17 \\
\hline \multirow{4}{*}{ 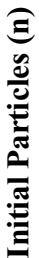 } & 2500 & 2.836 & 2.695 & 2.521 & 2.397 \\
\hline & 5000 & 2.681 & 2.416 & 2.249 & 2.165 \\
\hline & 10000 & 2.705 & 2.356 & 2.177 & 2.072 \\
\hline & 12500 & 2.747 & 2.466 & 2.121 & 1.992 \\
\hline
\end{tabular}

The spread of the value of minor loss coefficient of all simulations based on Table 4 is shown in Figure 8 .

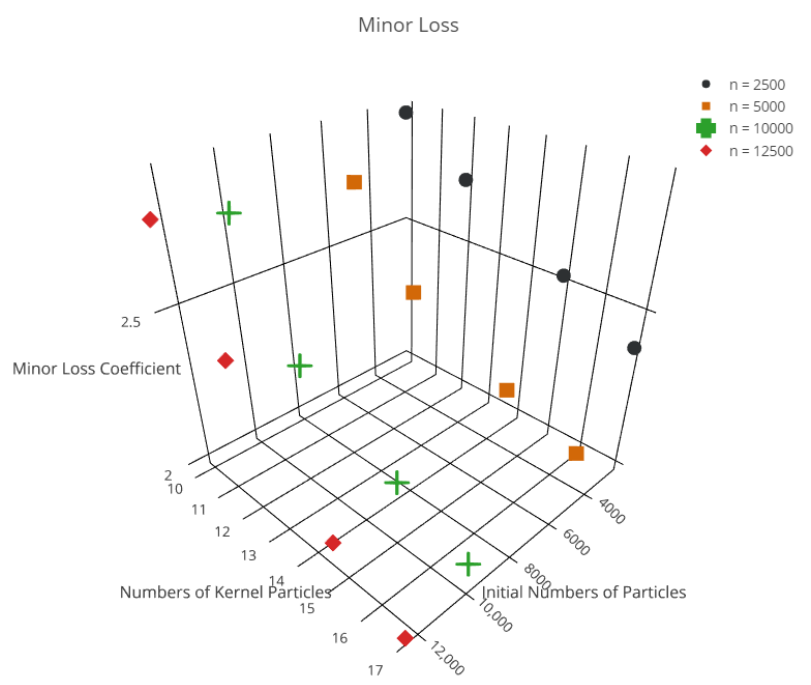

Fig. 8. The calculation of minor loss coefficient

The value of minor loss coefficient obtained varies based on the variation of the initial particles and kernel particles used. The scenario with the kernel particles of 10 particles gives the highest value of minor loss coefficient then decrease as the more increase the kernel particles used until on the kernel particles of 17 particles, the value of minor loss coefficient obtained is smaller. The range of the minor loss coefficient obtained is 1.992 to 2.836 . The large number of these minor loss coefficient is due to the large number of residues of the calculation of energy conservation law on all scenarios.

\section{Conclusion}

- The incompressible flow was reached on simulation of each scenario with the percentage of the value change of density to total density is near zero.

- The calculation of mass conservation law obtained the residue value near to zero.

- The calculation of energy conservation law obtained the residue value near to zero for $n=2500$ and 5000 particles with all variation of kernel particles studied in this research. However, there was high fluctuation of residue value if it used the number of initial particles from 10000 particles, which was needed the adjustment between the number of initial particles and the number of kernel particles used to reach the stability for computation and the residue value near to zero.

- The calculation of minor loss coefficient showed that the value of minor loss coefficient is more decrease as the larger number of kernel particles used at the range of 1.992 to 2.836 .

This research was supported by Universitas Indonesia through HIBAH PITTA funded by DRPM Universitas Indonesia No.5000/UN2.R3.1/HKP.05.00/2018. And we thank our colleagues from Department of Civil Engineering who provided assistance and support to this research.

\section{References}

1. B. C. Lydiana, Pengujian Keandalan Metode Smoothed Particle Hydrodynamics dalam Simulasi Aliran Air 3D Menerus. Thesis. Depok: UI-Ana. (2017)

2. S. A. Sitepu, Pengukuran Pengaruh Jumlah Partikel Terhadap Akurasi Metode Smoothed-Particles Hydrodynamics Untuk Menghitung Persamaan Kontinuitas Dan Persamaan Bernoulli Pada Aliran Melalui Penyempitan Pipa. Undergraduated Thesis. Depok: UI-Ana (2017)

3. B. C. Lydiana, Pengujian Metode Smoothed Particles Hydrodynamics Untuk Memenuhi Hukum Kekekalan Massa Dan Energi Aliran Air 3 Dimensi Ketika Melalui Penyempitan Pipa Vertikal. Undergraduated Thesis. Depok: UI-Ana (2016)

4. G. R. Liu, M. B. Liu, SMOOTHED PARTICLE HYDRODYNAMICS : A Meshfree Particle Method. World Scientific Publishing Co. Pte. Ltd (2003)

5. M. Kelager, Lagrangian Fluid Dynamics Using Smoothed Particle Hydrodynamics. Copenhagen: DIKU (2006)

6. G. R. Liu, M. B. Liu, Smoothed Particle Hydrodynamics (SPH) : an Overview and Recent Developments. Arch Computer Methods Engineering, 52 (2010)

7. J. J. Monaghan, Smoothed Particle Hydrodynamics. Annual Review Astronomy Astrophysics, 30, p. 543574 (1992),

8. J. J. Monaghan, Simulating Free Surface Flows with SPH. Journal of Computational Physics, p. 399-406 (1994) 
9. M. Becker, \& M. Teschner, Weakly Compressible SPH for Free Surface Flows. Eurographics/ ACM SIGGRAPH Symposium on Cmputer Animation, pp. 1-8 (2007)

10. M. Muller, D. Charypar, M. Gross, Particle-Based Fluid Simulation for Interactive Appliactions. SIGGRAPH Symposium on Computer Animation (2003)

11. M. C. Potter, D. C. Wiggert, B. Ramadan, T. Shih, Mechanics of Fluids, Fourth Edition. Stamford: Cengage Learning (2012) 